predictors are stable over different observation periods or if they are changing. The aim of our study was to assess the change in genderrelated predictors of mortality over 20 years of follow-up. Baseline data for this analysis come from epidemiological study of 2472 elderly residents of Krakow (age 65+) conducted in years 1986-1987. The multivariate Cox proportional hazard model was used to assess the changes of the role of predictors over of 20 years. In the male group, we have observed that the effect of coronary heart disease and diabetes mellitus on mortality were decreased with time. The importance of asthma as predictor of death was growing from 1.07 to 1.40 for the full follow-up. In the female group, protective effect of care about health and high functional activity were observed, however their impact decreased with increase of length of follow-up period. Poor SRH increase the mortality risk by $46 \%$ during the 5 years period and it decreased to $24 \%$ for 20 years of follow-up. Out of analysed chronic diseases the strongest predictor of mortality was diabetes mellitus with the over $60 \%$ increased mortality risk. We were able to show that the prognostic value of care about own health and healthy life-style, and high functional activity for women as well as chronic conditions present during the baseline study for men were changing with the length of observation.

\section{P1-274 PREVALENCE AND PREDISPOSING FACTORS FOR MALOCCLUSION AMONG BRAZILIAN PRESCHOOL CHILDREN}

doi:10.1136/jech.2011.142976e.66

${ }^{1} \mathrm{~A}$ Carvalho, ${ }^{1} \mathrm{~S}$ Paiva, ${ }^{*}{ }^{1} \mathrm{C}$ Viegas, ${ }^{1} \mathrm{~A}$ Scarpelli, ${ }^{1,2} \mathrm{~F}$ Ferreira, ${ }^{1} \mathrm{I}$ Pordeus. ${ }^{1} \mathrm{Federal}$ University of Minas Gerais, Belo Horizonte, Brazil, ${ }^{2}$ Federal University of Minas Gerais, Curitiba, Brazil

Introduction The aim of this study was to assess the prevalence of malocclusion in primary teeth and its predisposing factors.

Methods A randomised representative cross-sectional study was carried out in Belo Horizonte, Brazil, with 1069 preschool children between 60 and 71 months of age. A questionnaire addressing individual and behaviour characteristics of children was selfcompleted by parents. The oral examination was performed by a single dentist calibrated $(\kappa \geq 0.82)$ for the diagnosis of the following types of malocclusions: posterior crossbite, overjet ( $>2 \mathrm{~mm}$ ), anterior crossbite, anterior open bite and deep overbite. The chi-square and Fisher's exact tests were used, with the level of significance set at $5 \%$. The study was approved by the Ethics Committee of the Federal University of Minas Gerais.

Results The overall prevalence of malocclusion was $46.2 \%$. The specific prevalence of each malocclusion type was $13.1 \%$ for posterior crossbite, $10.5 \%$ for overjet, $6.7 \%$ for anterior crossbite, $7.9 \%$ for anterior open bite and $19.7 \%$ for deep overbite. No statistically significant associations were found between malocclusion and breast feeding, bottle feeding, pacifier sucking, finger sucking or nail biting $(p>0.05)$. No statistically significant associations were found between malocclusion and the presence of these habits after 2 years of age ( $p>0.05)$. No statistically significant associations were found between malocclusion and parents' report of the occurrence of stuffy nose, open mouth, nose operation, throat operation or sinusitis ( $p>0.05)$.

Conclusion The prevalence of malocclusion was high, but the predisposing factors investigated were not associated to the presence of malocclusion.

Funding Supported by FAPEMIG and CNPq.

\section{P1-275 HEARING HEALTH IN ELDERLY: A POPULATION-BASED STUDY IN SÃO PAULO CITY, BRAZIL}

doi:10.1136/jech.2011.142976e.67

K M Paiva,* S M Alencar, C L G Cesar, M B de Azevedo Barros, L Carandina, M C G P Alves, M Goldbaum. University of São Paulo, São Paulo, Brazil

Introduction Hearing loss in older people is one of the most prevalent chronic conditions. In 2004, was implemented in Brazil the Hearing Health Attention National Policies. This policy contains programs for prevention, diagnostic and rehabilitation, including donations of hearing aids and providing education about hearing health.

Methods Data are from the Survey of Health of São Paulo (ISA-Capital, 2008), a population-based cross-sectional study $(n=3271)$. This survey utilised the same methodology the previous surveys conducted at 2001 and 2003. We analysed the subgroup of elderly ( 60 years and above $-n=924)$. We used the $\chi^{2}$ test of association and analysis of Poisson regression (significance level: 0.05)

Results The prevalence of self-reported hearing loss in elderly in this study was $12.4 \%$. This prevalence was higher in men than women (RP: $1.5 ; \mathrm{p}=0.01$ ) and in higher ages (more 80 years) than in 60-69 years (RP: $2.2 ; p=0.00$ ). $24,4 \%$ of them did not know the cause of hearing loss and $42 \%$ related that old age is cause of this deficit. $38.8 \%$ of interviewed said that they do not need medical assistance or treatment rehabilitation.

Conclusion The unknowledge of the elderly about the causes of hearing loss and the need to assistance suggests that the government's policies needs to evaluate and improve the process of assisting in these people with hearing impairment, assuring its effectiveness. Since ageing is getting wide, developing countries like Brazil, need to meet new demand from this segment of the population.

\section{P1-276 A HISTORICAL COHORT STUDY TO DETERMINE THE PREVALENCE OF COMMON CHRONIC RESPIRATORY DISEASES AND MEDICATION USE IN DRUG MISUSERS}

doi:10.1136/jech.2011.142976e.68

F Palmer, ${ }^{*}$ M Jaffray, M Moffat, C Matheson, A Coutts, J Haughney. Centre of Academic Primary Care, University of Aberdeen, UK

Introduction A local substance misuse study and anecdotal evidence from primary care suggested many methadone patients have respiratory disease and/or respiratory prescriptions.

Method This exploratory study used a historical cohort design with matched controls. Analysis of PCCIU (Primary Care Clinical Informatics Unit) GP consultation data were conducted. The prevalence of respiratory diseases and respiratory prescriptions between drug misusers and controls were compared.

Results The PCCIU consultation data were taken from a cohort of 18570 patients (9285 per group), of whom, 64\% ( $n=11885)$ were male and $75.7 \%(n=14060)$ were aged $31-59$ years. The results revealed an increased prevalence of chronic respiratory disease in drug misusers vs controls. Drug misusers were more likely to be prescribed chronic respiratory disease medications than controls. Adjustment for smoking status revealed drug misusers still have significantly increased odds of having respiratory disease and/or receiving respiratory prescriptions. (Abstract P1-276 table 1). 